\title{
Intelligent Safety System for Women Security
}

\author{
Sutar Megha ${ }^{1}$, Ghewari M.U. ${ }^{2}$ \\ Student, E\&TC Department, DACOE, Karad, Maharashtra, India ${ }^{1}$ \\ Assistant Professor, E\&TC Department, DACOE, Karad, Maharashtra, India ${ }^{2}$
}

\begin{abstract}
Now-a-dayslife is full of rush and India is fastly moving on the path of being a promising super power and an economic hub. But this goal can be achieved if large number of woman participate in the development process. Today's modern women have acquired high offices in India including that of the president, prime minister, speaker of the loksabha and even in field of aeronautics, military, IPS, IAS, etc. Even today women have achieved top positions in job and society, yet they are facing problems such as physical harassment and sexual assault. The cases of harassment and rapes on women are increasing hence security issue for such woman is more important. So it is essential to develop system to provide security to women. The system allows women to protect herself from attackers. By pressing the button of the system a helping message along with her location will be transmitted by the system to the police station and her few relatives, so that they will get aware of her current situation. Along with the message she is also able to give shock to the attacker with the help of system. So she get some time to get rescue from that attacker.
\end{abstract}

Keywords: ARM Controller, GPS, GSM, Women Security

\section{INTRODUCTION}

Since last few decades the status of women in India has VithUapp:

been going through lot of changes. To remain part of fast It is mobile application used in smart phone in which, life women also works a lot to survive and supports their when power button is pressed two times helping message family.

They work at different places like BPO's, call centres ,IT Sent information (location) is updated after every two firms, and so many places like it. But even today's women minutes[2].

is still facing many social challenges in India and are often victims to violent crimes.

SHE (Society Harnessing Equipment):

Three engineers designed a clothing which has electric

Thomson Reuters had said that," according to global poll, India is the 4th most worst country in the world and the dangerous country for women among growing 20 countries." Day by day the attacks on women are increasing and in some cases she is not even able to take her mobile and dial up to police ,this system will help women in such cases to inform about attacks and also in giving her exact location to nearby police station for necessary action.

The greatest motivation for this system was the Delhi Nirbhaya case that triggered the whole nation. Women will be provided with a device that includes GSM, GPS, Shock Generator. By pressing the button, a helping message will be sent to nearby police station and her relatives informing about her exact location.

\section{LITERATURE REVIEW}

Security is most important factor for safety of women. Today's women require help for their safety so there is need for developing a portable system for women security [1]. Recently existing security system for women are as follows:

circuit. $3800 \mathrm{kV}$ of current is generated by circuit.

It will generate 82 electric shocks which will help women to get recue from the situation in case of multiple attacks.

It will not harm the women(user) because the clothing is made up of two layers[2].

We got idea of including buzzer in system to grab attention of nearby people so that she will get help from them [3].

The I Safe app describes that whenever the women is in danger by this app on mobile the contacts saved on her mobile get her location and also a message that she is in danger[4].

Today's demand is to be safe and secure. So the women need a gadget which is small in size and can be carried easily with her which help her in the crime incidents[5].

III. SYSTEM DESCRIPTION

A. Block Diagram 
IARJSET

Vol. 4, Special Issue 2, January 2017

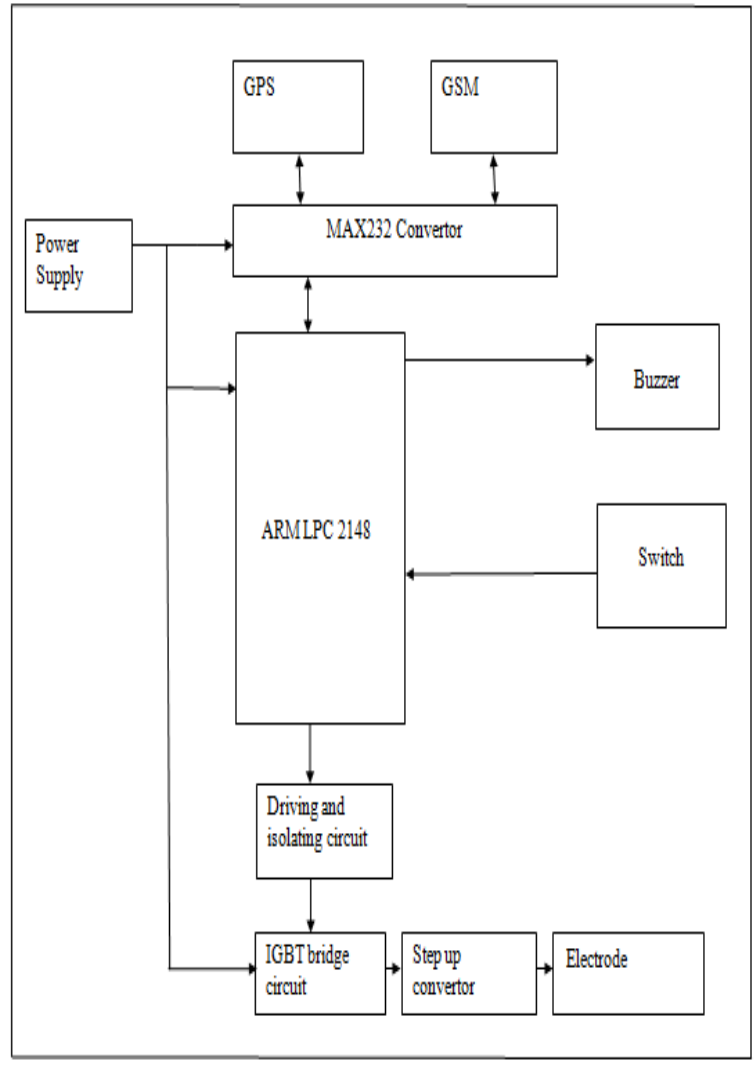

Fig.1. Block diagram

\section{B. Working}

Whenever woman will feel unsafe she will press the button of the device, that event will be recognized by LPC 2148 controller. Then controller will generate control signal for GPS system, it will send control signal through MAX 232 to GPS module. GPS will get activated, so it will track the exact location of the victim and send this information back to ARM controller through MAX 232 interface.

ARM controller will generate control signal for GSM system, then GSM system will get activated. It will send helping message along with the tracked location to the already stored contact numbers and police station. The location will get updated after every two minute and continuously sent location to the already stored contact numbers and police station.

Simultaneously, whenever she will press the button of the device, controller will generate control signal to shock generator. Shock generator will get activated at output we will get shock pulses so that victim will give shock to the attacker to protect herself. Shock generator is operated through driving and isolating circuit. Isolating circuit will provide isolation between ARM controller and shock generator to protect ARM from high voltage of shock generator.

\section{Flow chart}

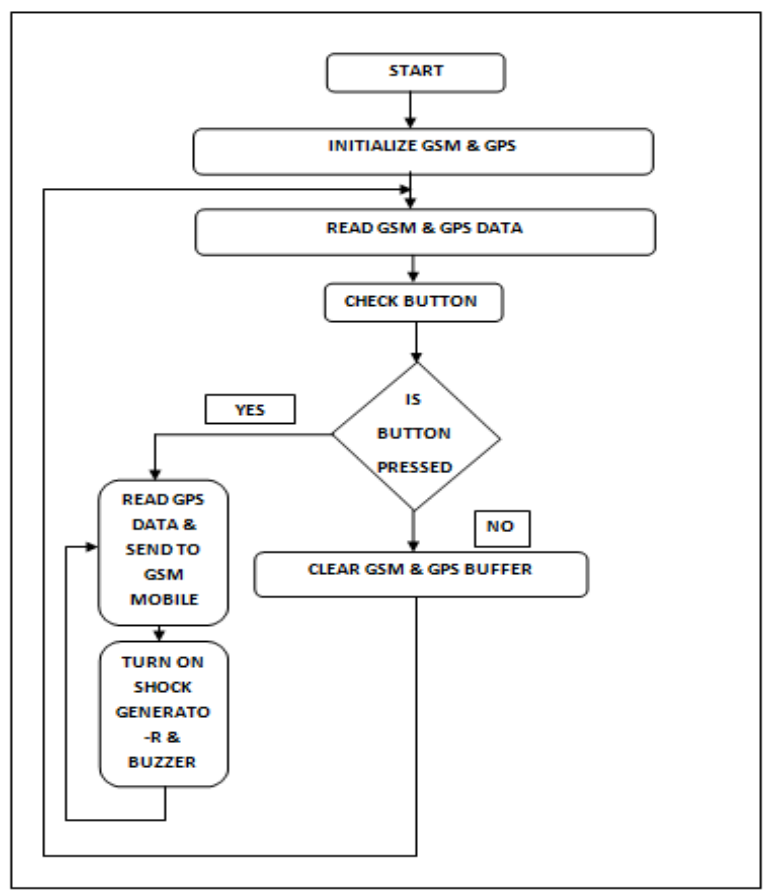

Fig.2. Flowchart

D. ARM Controller (LPC 2148)

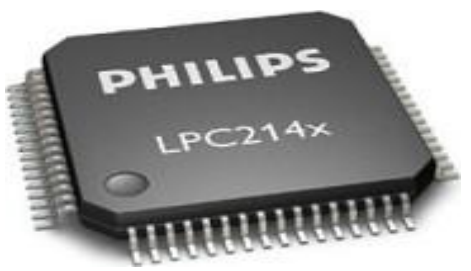

Fig.3. LPC 2148(Top View)

In this system LPC 2148 is used, which is ARM 7 microcontroller.ARM 7 microcontroller allows us to access many inputs which can overcome microcontroller's drawback. It consists of emulation along with embedded trace support which is used to combine the microcontroller with embedded high speed flash memory. A 32-bit code execution can be achieved at maximum clock rate with the help of wide memory interface and also unique accelerator architecture is used. A code can bee reduced to $30 \%$ of minimal performance penalty for critical code of 16-bit instruction set. As they have small size and lower power consumption, they have number of ideal applications. Miniaturization is very important requirement. A serial communication interface is supported by it.

\section{E. Global System for Mobile(GSM)}

The below fig.4.GSM Module is refered from "Open source electronics projects". SIM900 is used in various customer applications. It comes in SMT module and supports quadband GSM/GPRS. It is used for transmitting data, voice and fax. It provides GSM/GPRS $850 / 900 / 1800 / 1900 \mathrm{MHz}$ performance with low power requirement. Due to its small size having dimensions $24 \mathrm{~mm} * 24 \mathrm{~mm} * 3 \mathrm{~mm}$. 
Vol. 4, Special Issue 2, January 2017
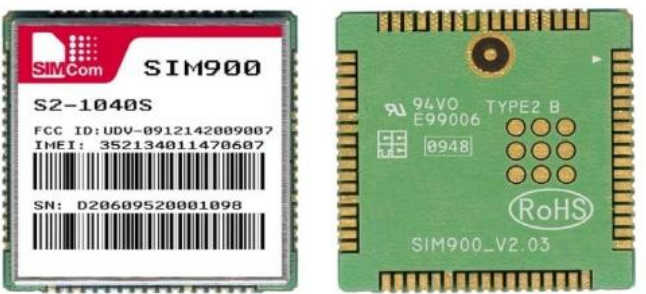

Fig.4. GSM Module

It is used in M2M applications as it fulfill all space requirement. A powerful single chip processor which are having AMR926EJ - S core is used to design SIM900 communication with controller is done through AT command. Software power on and reset is also provided. It is controlled and configured through its UART. It is also possible to use SIM900 with arduino ,Raspberry pi, PIC, AVR, ARM and AT commands are used to control it. It can be connected through USB portto the computer.

\section{F. Global Positioning System(GPS)}

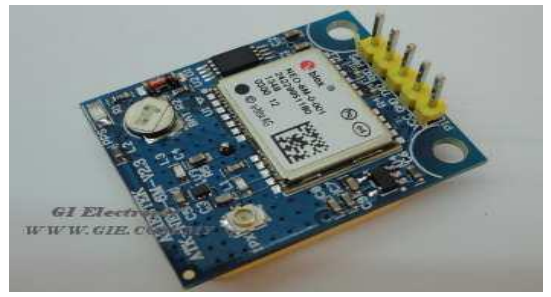

Fig.5. GPS Module

The above fig.5.GPS Module is referred from "GI Electronics". GPS receivers are used to locate the position of the user with the help of GPS satellite. NEO-6 module is a GPS receiver. GPS consists of constellation of 24 satellites and their earth station. It is basically used for radio navigation over a world. Global Navigation Satellite System Network is used by GPS TRACKING SYSTEM. The information about the location, speed, direction is transmitted to GPS receivers using microwave signals. The high performance ublox 6 positioning engine is used in NEO-6module. It's size is very small upto $16^{*} 12.2 *$ $2.4 \mathrm{~mm}$. These modules are cost effective and flexible due to its small size. NEO-6 module can also be used with battery operated mobile devices due to its low power requirement and compact architecture. U-blox 6 positioning engine has 2 million correlators. So simultaneous time / frequency space searching becomes possible. Itenable module to serach satellite without delay. Jamming sources are suppressed .and multipath effects are also reduced by using innovative design and technology. Hence NEO-6 most challenging environment.

\section{G. Shock Generator}

Shock generator consists of:

\section{IGBT Bridge Circuit:}

IGBT circuit is used to convert DC voltage into AC voltage.

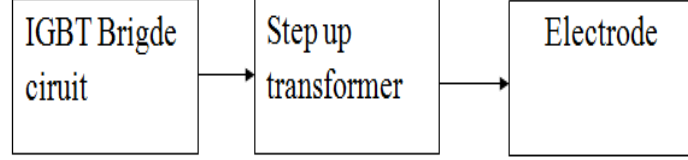

Fig.6. Block Diagram of Shock Generator

\section{Step Up Transformer:}

AC voltage is boosted to upto $80 \mathrm{~V}-108 \mathrm{~V}$.

Electrode:

Boosted voltage is applied to an electrode, so that it will give shock to the attacker. Electrode is nothing but copper metal wire.

\section{CONCLUSION}

Nowadays security is very important aspect for everyone, mostly for women who are facing various harassment problems. This system is helpful for such women to escape from the dangerous situation

\section{ACKNOWLEDGMENT}

We would like to thank sincerely tour guide Miss. M.U.Ghewari for her invaluable guidance, constant assistance, support and constructive suggestions for the betterment of this project work. We would like to express our deep sense of gratitude to our principal Prof. Dr. J.R.Patil for his continuous efforts in creating a competive environment in our college and encouraging throughout this course. We would like to convey our heartfelt thanks to our HOD Prof. P.J. Chorage for giving us the opportunity to embark upon this topic and for his continued encouragement. We also wish to thank all the staff members of the department of E\&TC engg for helping us directly or indirectly for the project work.

\section{REFERENCES}

[1] Ashlesha Wankhede, Ashwini velankar, Priyanka Shinde "PORTABLE DEVICE FOR WOMEN SECURITY". IJRET, eISSN:2319-1163|p ISSN:2321-7308

[2] Prof. BasavrajChougula,ArchanaNaik, Monika Mono, PriyaPatil, Priyanka Das "SMART GIRLS SECURITY SYSTEM ", IJAIEM, ISSN 2319-4847, Volume 3, Issue 4, April 2014.

[3] Daniel Clement, Kush Trivedi, SaloniAgarwal,Shikha Singh "AVR Microcontroller Based Wearable Jacket for Women Safety”. IRJET, e-ISSN:2395-0056, p-ISSN:2395-0072,Volume 03,Issue 05|May 2016.

[4] Dr. Sridhar Mandapati, SravyaPamidi, SriharithaAmbati "A Mobile Based Women Safety Application(I Safe Apps)", IOSR-JCE, eISSN:2278-0661, p-ISSN:2278-8727, Volume 17,Issue 1, VerI(Jan-Feb.2015), PP 29-34.

[5] B.Vijaylakshmi, Renuka.S, PoojaChennur, Sharangowda.Patil "SELF DEFENSE SYSTEM FOR WOMEN SAFETY WITH LOCATION TRACKING AND SMS ALERTING THROUGH GSM NETWORK”. IJRET,eISSN:2319-1163|pISSN:2321-7308

[6] NishantBhardwaj,NitishAggarwal "Design and Development of 'Suraksha'-A Women safety Device”. IJICT,ISSN:0974-2239, Volume 4, No.8(2014), pp.787-792.

[7] J.Nagraju,V.Sadanandam "Self Salvation-The Women's Security Module", IJIREC, Volume 3,Issue 1,January 2016,PP 13-19,ISSN 2349-4042 and ISSN 2349-4050.

[8] AbhijeetParadkar, Deepak Sharma "All In One Intelligent Safety System For Women Security". International journal of computer applications(0975-8887), Volume 130-No.11,November 2015. 